\title{
LAS EXPERIENCIAS ESTUDIANTILES DURANTE LOS “AZOS" ARGENTINOS EN PERSPECTIVA LATINOAMERICANA
}

\section{STUDENT EXPERIENCES DURING THE ARGENTINE "AZOS" IN LATIN AMERICAN PERSPECTIVE}

\author{
JUAN SEBASTIÁN CALIFA (UBA / CONICET) \\ Instituto de Historia Argentina y Americana Dr. Emilio Ravignani \\ Universidad de Buenos Aires \\ Consejo Nacional de Investigaciones Científicas y Técnicas \\ iscalifa@hotmail.com
}

\section{MARIANO MILLÁN (UBA / CONICET)}

Instituto de Historia Argentina y Americana Dr. Emilio Ravignani

Universidad de Buenos Aires

Consejo Nacional de Investigaciones Científicas y Técnicas

marianomillan82@gmail.com

\section{Resumen:}

En este ensayo de interpretación reflexionamos sobre las experiencias estudiantiles en los "azos" argentinos de fines de los años sesenta y principios de los setenta del siglo XX a contraluz con otras movilizaciones estudiantiles en la región. Se pondrá atención a las estrategias que establecieron los estudiantes, subrayando las alianzas que trazaron. Para ello consultamos la literatura específica, así como los resultados que han comenzado a mostrar nuestras investigaciones.

Palabras clave:

Movimientos estudiantiles - América Latina - Años sesenta - Revueltas urbanas - Análisis comparativo

\begin{abstract}
:
In this interpretation essay were flect on the student experiences in the Argentine "azos" of the late sixties and early seventies of the twentieth century back lit with other student mobilizations in the region. Our attention will be given to the strategies that the students established, highlighting the alliances they drew. For this we consult the specific literature as well as the results that have begun to show our research.
\end{abstract}

\section{Keywords:}

Student movements - Latin America - sixties - urban riots - comparative analysis 


\title{
LAS EXPERIENCIAS ESTUDIANTILES DURANTE LOS “AZOS" ARGENTINOS EN PERSPECTIVA LATINOAMERICANA
}

\author{
JUAN SEBASTIÁN CALIFA (UBA / CONICET)
}

jscalifa@hotmail.com

MARIANO MILLÁN (UBA / CONICET)

marianomillan82@gmail.com

\section{Introducción}

En el presente ensayo ofrecemos una serie de reflexiones, basadas en la bibliografía, sobre los movimientos estudiantiles de Argentina durante las revueltas de fines de los años ' 60 y principios de los '70, los "azos", a partir de sus similitudes y contrastes con las manifestaciones de sus pares latinoamericanos. Bajo este rótulo aparecen situaciones locales disímiles que hasta ahora han sido copiosamente estudiadas desde el punto de vista de su singularidad histórica, pero poco exploradas de modo comparativo y con una perspectiva más englobante. En general el sufijo alude a protestas urbanas que implicaron grandes sublevaciones de masas contra el orden instituido. Estas movilizaciones recurrieron rápidamente a las calles desafiando por breves lapsos el monopolio de la violencia estatal y desnudaron las arbitrariedades represivas de un régimen de dominación más coercitivo que consensual. El hecho de que sus gobiernos debieran recurrir a fuerzas militares para refrenar tales levantamientos da cuenta de ello, al tiempo que exhibe la magnitud de la disrupción social que los "azos" desataron.

Por la trascendencia histórica de los hechos estudiantiles en los países de la región, nos enfocaremos en los eventos de Ayacucho, Ciudad de México, Montevideo y Río de Janeiro, acaecidos en países marcados por el autoritarismo estatal. Como señaló uno de los intelectuales pioneros en abordar la cuestión, “... el activismo de los estudiantes latinoamericanos [...] decae cuando se hallan en el poder gobiernos democráticos y aumenta cuando se enfrentan a gobiernos autoritarios".

En primer lugar, identificamos realidades regionales/locales convergentes y divergentes, a grandes rasgos, en dos tipos de territorios. Por una parte, las áreas en las que las transformaciones socioeconómicas recientes destruyeron relaciones productivas de larga data, dislocando la estructura social y desarticulando relaciones de poder tradicionales. Por otra, las geografías donde la "modernización" tuvo resultados más cercanos a los buscados, con nuevas actividades económicas, crecimiento de la población e innovación en el campo cultural.

En segundo término, cotejamos las composiciones de ciertos movimientos estudiantiles, distinguiendo actores y estrategias. Ubicamos desde un punto de vista ideológico a los grupos que componían estos movimientos estudiantiles y protagonizaron, con diferente intensidad, las acciones colectivas contenciosas.

\footnotetext{
${ }^{1}$ Albornoz, Orlando, Estudiantes y desarrollo político, Caracas, Monte Ávila Editores, 1968, p. 135 y ss.
} 
En un tercer momento describimos los principales rasgos de la política universitaria y de la contienda política de estos países después de las revueltas. Con ello pretendemos ofrecer herramientas para comprender la incidencia de estas experiencias estudiantiles en la historia reciente de América Latina.

El conocimiento sobre el movimiento estudiantil latinoamericano presenta ciertos contrastes. El largo ciclo global de manifestaciones despertó un interés político e intelectual generalizado. Un primer conjunto de trabajos sociológicos de mediados de los años ' 60 , donde sobresalen los conservadores catedráticos norteamericanos, hicieron foco en las tensiones derivadas de la persecución de la modernización política, social y económica, donde la universidad jugaría un rol clave. ${ }^{2}$ Las carencias de presupuesto y de profesores de tiempo completo competentes llevarían a la formación de comunidades académicas precarias. En un escenario donde existía la tradición de la Reforma de 1918 y una poderosa subcultura estudiantil, estas circunstancias podrían desencadenar un proceso de radicalización.

Para finales de los años ‘ 60 muchos estudiantes formados a lo largo de la década ofrecieron lecturas marxistas de las movilizaciones. El venezolano Héctor Silva Michelena y su colega alemán Heinz Sonntag, por ejemplo, sostuvieron que se vivía una etapa de "extrañamiento positivo", caracterizado en el estudiantado por la humanización, la exigencia de un desarrollo nacional propio y la apelación a la violencia revolucionaria. ${ }^{3}$ Entre estos análisis resultó paradigmática la influyente obra de Juan Carlos Portantiero. ${ }^{4} \mathrm{El}$ intelectual argentino analizó la radicalización estudiantil como una resultante, fundamentalmente, de la devaluación de los títulos en el contexto de crisis del capitalismo dependiente latinoamericano, dejando en un nivel de incidencia subalterna las acciones dentro de los claustros.

Durante el ocaso de los años '70 la producción académica sobre el movimiento estudiantil había mermado, en consonancia con el declive de su presencia en contextos de nuevas y más represivas dictaduras. Ya con los regímenes militares en retirada, el intelectual chileno José Joaquín Brunner cuestionó seguir hablando del movimiento estudiantil latinoamericano y recomendó pensarlo en plural. $^{5}$

En Argentina, poco más tarde, durante el proceso de recreación de un campo de estudios sobre los años '60 y '70 empezaron a plantearse hipótesis explicativas del fenómeno estudiantil. Se sostuvo que tras el golpe de Estado y la intervención universitaria de 1966 sobrevino una etapa de radicalización caracterizada por la crisis del reformismo. ${ }^{6}$ La peronización ${ }^{7}$ y el surgimiento de la nueva izquierda ${ }^{8}$ fueron los principales vectores de un giro ideológico donde predominó una escasa atención a los problemas universitarios. ${ }^{9}$ Estas conjeturas fueron publicadas sin analizar bases de datos exhaustivamente construidas, ni enfocarse específicamente en el movimiento estudiantil, sino

\footnotetext{
2 Por su carácter sintético: Cf. Lipset, Seymour, Estudiantes universitarios y politica en el tercer mundo, Montevideo, Alfa, 1965; Solari, Aldo, "Introducción”, en Solari, Aldo (comp.), Estudiantes y Política en América Latina, Caracas, Monte Ávila Editores, 1968 y Scott, Robert, "Student Political Activism in Latin America”, en Lipset, Seymour y Altbach, Philip (comps.), Student in Revolt, Boston, Hoyghton Mifflin Company, 1969, pp. 403-431.

${ }^{3}$ Cf. Silva Michelena, Héctor y Sonntag, Heinz, Universidad, dependencia y revolución, Caracas, Academia Nacional de Historia, 1970.

${ }^{4}$ Publicada en italiano durante 1971 y luego en castellano. Cf. Portantiero, Juan Carlos, Estudiantes y política en América Latina, México D.F., Siglo XXI, 1978.

${ }^{5}$ Brunner, José Joaquín, El movimiento estudiantil ha muerto. Nacen los movimientos estudiantiles. Santiago de Chile, FLACSO, 1985.

${ }^{6}$ Sigal, Silvia, Intelectuales y poder en la década del sesenta. Buenos Aires: Puntosur, 1990.

${ }^{7}$ Barletta, Ana María, "Peronización de los universitarios (1966-1973). Elementos para rastrear la constitución de una política universitaria peronista", Pensamiento Universitario, núm. 9, Quilmes, 2001, pp. 82-89.

${ }^{8}$ Tortti, María Cristina, "Protesta social y 'nueva izquierda' en la Argentina del Gran Acuerdo Nacional”, en Camarero, Hernán, Pozzi, Pablo y Schneider, Alejandro (comps.), De la Revolución libertadora al menemismo, Buenos Aires, Imago Mundi, pp. 135-160.

9 Sarlo, Beatriz, La batalla de las ideas (1943 -1973), Buenos Aires, Emecé, 2001.
} 
en "los universitarios". Sin embargo, organizaron un sentido común sobre el período que sólo en años recientes comenzó a desandarse.

En el caso mexicano, por el peso decisivo del movimiento estudiantil de 1968 sobre la dinámica política, desde la obra pionera de Ramón Ramírez ${ }^{10}$ se cuenta con una documentada cronología de hechos, al menos para la Ciudad de México, que ha servido de fundamento a las discusiones posteriores. Aunque con menor volumen bibliográfico, algo similar puede señalarse sobre Brasil y Uruguay, donde los trabajos de Arthur Poerner ${ }^{11}$ y Carlos Bañales y Enrique Jara ${ }^{12}$ establecieron la serie de eventos que son ineludibles para cualquier análisis de las movilizaciones de dicho año. En Perú las investigaciones tuvieron un auge entre fines de la década de 1980 y principios de la siguiente, en el marco del conflicto interno. La emergencia y consolidación del Partido Comunista del Perú Sendero Luminoso (PCP-SL) se convirtió en el eje de los trabajos sobre la Universidad de San Cristóbal de Huamanga (UNSCH) de Carlos Degregori ${ }^{13}$ o el reciente de Manuel Granados, ${ }^{14}$ mientras Nicolás Lynch analizó la radicalización en San Marcos. ${ }^{15}$

Durante los años '60 y '70 los analistas adjudicaron una potencialidad transformadora a la "deslocalización" de lo universitario. Paradójicamente, a fines de la centuria el mismo enfoque demostraba la impotencia de la juventud sesentista. ${ }^{16}$ En el nuevo siglo, libros como los de Juan Sebastián Califa ${ }^{17}$ o Vania Markarián ${ }^{18}$, por citar ejemplos con diferencias pronunciadas, posicionaron las cuestiones universitarias y juveniles en el centro de los movimientos estudiantiles, sin renunciar a localizar sus acciones en procesos más amplios. A su vez, esta producción presenta otro contraste con lo escrito al calor de los acontecimientos. Las obras compiladas por Renate Marsiske, ${ }^{19}$ Pablo Bonavena y Mariano Millán ${ }^{20}$ o José René Rivas Ontiveros, Ana Sánchez Sáenz y Gloria Tirado Villegas ${ }^{21}$ muestran que los textos recientes no se propusieron explicaciones generales de la época a través del accionar juvenil, como el ensayo clásico de Alain Touraine, ${ }^{22}$ sino realizar estudios de caso. Asimismo, con la excepción de algunos trabajos como los de Andrés Donoso Romo, ${ }^{23}$ Laura Luciani $^{24}$ o Millán, ${ }^{25}$ las comparaciones con base en la investigación empírica reciente todavía resultan escasas.

\footnotetext{
${ }^{10}$ Ramírez, Ramón, El movimiento estudiantil de México (julio-diciembre de 1968), México D.F., ERA, [1969] 2008.

11 Poerner, Arthur, O poder jovem. História da participação políticas dos estudantes brasileiros, Rio de Janeiro, Civilização Brasileira, 1968.

12 Bañales, Carlos y Jara, Enrique, La rebelión estudiantil, Montevideo, ARCA, 1968.

${ }^{13}$ Degregori, Carlos, El surgimiento de Sendero Luminoso. Ayacucho 1969-1979, Lima, IEP, 2014.

${ }^{14}$ Granados, Manuel, La Universidad de Huamanga y el PCP Sendero Luminoso, Lima, Testigo13, 2019.

${ }^{15}$ Lynch, Nicolás, Los jóvenes rojos de San Marcos. El radicalismo universitario de los años setenta, Lima, El Zorro de Abajo, 1990.

${ }^{16}$ Sarlo, Beatriz, La batalla de..., op. cit.

${ }^{17}$ Califa, Juan Sebastián, Reforma y Revolución. La radicalización politica del movimiento estudiantil de la UBA 1943-1966, Buenos Aires, EUDEBA, 2014.

${ }^{18}$ Markarián, Vania, El 68 uruguayo. El movimiento estudiantil entre molotovs y música beat, Buenos Aires, Universidad Nacional de Quilmes, 2012.

19 Profesora de la UNAM, lleva compilados cinco volúmenes sobre la Historia Crítica del Movimiento Estudiantil Latinoamericano.

${ }^{20}$ Bonavena, Pablo y Millán, Mariano (eds.), Los ‘68 latinoamericanos. Movimientos estudiantiles, política y cultura en México, Brasil, Uruguay, Chile, Argentina y Colombia, Buenos Aires, CLACSO-IIGG, 2018.

${ }^{21}$ Rivas Ontiveros, José René, Sánchez Sáenz, Ana y Tirado Villegas, Gloria, Historia y memoria de los movimientos estudiantiles: a 45 años del 68, México D.F., UNAM, 2013, Vols. I y II.

22 Touraine, Alain, La sociedad post-industrial, Barcelona, Ariel, 1971.

${ }^{23}$ Donoso Romo, Andrés, "El movimiento estudiantil mexicano de 1968 en clave latinoamericana: aproximación a las nociones de educación y transformación social”, Historia Crítica, núm. 63, 2017, pp. 137-157.

${ }^{24}$ Luciani, Laura, "Movimientos estudiantiles latinoamericanos en los años sesenta”, Historia y memoria, núm. 18, 2019, pp. 77-111.

${ }^{25}$ Millán, Mariano, "Movimiento estudiantil y procesos políticos en Argentina y Brasil (1964-1973)", Século XXI, núm. 2, 2012, pp. 73-112 y “Estudiantes y política en Argentina y Chile (1966-1973)”, Izquierdas, núm. 16, 2013, pp. 31-54.
} 
Por todo ello, refiriendo a descripciones ya realizadas, comparamos algunos aspectos de aquellas grandes confrontaciones con el objetivo de reflexionar sobre el caso argentino a contraluz de lo sucedido en otros países.

\section{Universidad, estudiantes, desarrollo, modernización y conflicto}

Las grandes movilizaciones estudiantiles de fines de los años ' 60 y principios de los ' 70 constituyen uno de los puntos álgidos de un proceso histórico más prolongado, que Diana Sorensen ${ }^{26}$ y Van Goose $^{27}$ llamaron "largos años sesenta". Respecto del activismo en las facultades, desde el meridiano de la década de 1950 pueden contarse episodios de distinta magnitud en Bogotá (1954), Buenos Aires (1956/8), Ciudad de México (1956 y 1958), La Habana (1958) o Montevideo (1958). Varios fueron conflictos ligados a las características del sistema universitario, ya sea la disputa por la conservación del monopolio estatal en la emisión de títulos, como durante la "Laica o Libre" en Argentina, o su democratización, como con la promulgación de la Ley Orgánica de Universidades en Uruguay. Casi todos involucraron a otros actores sociales, como los conductores de los camiones mexicanos o los soldados colombianos que retornaban de Corea. Generalmente, durante la contienda política se fueron ampliando los reclamos estudiantiles, cuestionando a los gobiernos y sus posicionamientos internacionales y llevando las formas de acción hacia modalidades transgresivas, en escenarios callejeros con el recurrente uso de la violencia, rasgos distintivos de lo que Sidney Tarrow, Dough Mc Adam y Charles Tilly identificaron como radicalización. ${ }^{28}$

Al tiempo que se producían aquellos acontecimientos, grandes factores de poder a escala global, por ejemplo, corporaciones empresarias como la de Nelson Rockefeller, el gobierno de los Estados Unidos, los partidos comunistas o la Iglesia Católica, identificaron la universidad como un escenario gravitante. Las facultades prácticamente monopolizaban la investigación y la formación profesional, científica y dirigencial, elementos centrales para alcanzar la ansiada "modernización". En consonancia, las matrículas universitarias crecieron aceleradamente en Occidente, ya sea por iniciativa de los actores mencionados y/o por fuerzas de las sociedades civiles, con distintos niveles de cooperación y enfrentamiento. ${ }^{29}$

En este proceso, Argentina hacía punta en Latinoamérica. Según datos de UNESCO, su tasa bruta de escolarización universitaria (calculada sobre la franja etaria de 20 a 24 años), había pasado del 5,2 en 1950, a 11,3 en 1960 y finalmente al 14,2 en 1970. Con más de 270 mil universitarios nuestro país estaba a las puertas de la universidad de masas, según la escala de Martin Trow. ${ }^{30}$ No obstante, en otras naciones de la región también se habían incrementado notablemente esas cifras, experimentando lo que Brunner denominó "la gran transformación". ${ }^{31}$

En ese contexto, tras la Revolución Cubana la confrontación global agudizó las contradicciones regionales preexistentes en el marco de la Guerra Fría. ${ }^{32}$ La radicalización estudiantil se potenció así en los tempranos años ' 60 , fisurándose la aquiescencia sobre los sistemas universitarios como herramientas vitales para el desarrollo. Los debates sobre el carácter de la modernización, que

\footnotetext{
${ }^{26}$ Cf. Sorensen, Diana, A Turbulent Decade Remembered: Scenes from the Latin American Sixties, Stanford, Stanford University Press, 2007.

${ }^{27}$ Cf. Van Goose, Rethinking the New Left: An Interpretative History, Nueva York, Palgrave/Macmillan, 2005.

${ }^{28}$ Mc Adam, Dough, Tarrow, Sidney y Tilly, Charles, Dinámica de la contienda política, Barcelona, Hacer, 2005, p. 71.

${ }^{29}$ Hobsbawm, Eric, Historia del siglo XX, Buenos Aires, Crítica, 2002, pp. 298-301.

${ }^{30}$ Cf. Trow, Martin, "Reflections on the Transition from Elite to Mass to Universal Access: Forms and Phases of Higher Education in Modern Societies since WWII", 2005, en línea https://escholarship.org/content/qt96p3s213/qt96p3s213.pdf?t=krnnkm\&nosplash=09fe2aa3c65bfe807e4184cef5 d8bdc2, consulta: 4/10/19.

31 Cf. Brunner, José, Educación superior en América Latina: cambios y desafíos, Santiago de Chile, Fondo de Cultura Económica, 1990.

${ }^{32}$ Cf. Brands, Hall, Latin America's cold war, Boston, Harvard, 2012.
} 
tuvieron a los estudiantes como principales animadores, se encuentran estrechamente relacionados con el descrédito de los gobiernos en las facultades.

Cuando las dictaduras (Argentina, Brasil, Perú) o los gobiernos autoritarios (México y Uruguay) de la segunda mitad de los años '60 realizaron sus incursiones en los claustros para desterrar el comunismo real o supuesto, expresaban un cambio de énfasis en la orientación de las clases dominantes del continente y el hemisferio: las preocupaciones habían pasado de la modernización a la Seguridad Nacional. Sin embargo, esos ataques, como el asesinato de Santiago Pampillón en Córdoba en septiembre de 1966, la "Masacre de Playa Vermelha" en Río de Janeiro el mismo año o el abatimiento del estudiante Líber Arce en Montevideo durante 1968, por mencionar sólo algunos, no eran los primeros.

Naturalmente, existen variaciones en las fechas de los golpes de Estado o giros autoritarios. Sin embargo, en todos los países registramos con variable intensidad campañas contra la Universidad pública, su autonomía y organización reformista con el cogobierno estudiantil a la cabeza (donde existía) impulsadas por los mismos actores sociales.

En Argentina las iniciativas desarrollistas y modernizadoras tuvieron su esplendor desde la década del ' 50 , siendo especialmente influyentes para numerosos proyectos en las zonas extrapampeanas. En algunos casos, como el de Córdoba, potenciando esfuerzos de industrialización de los decenios previos; en otros, como en el de Tucumán, desarticulando relaciones de producción de más de un siglo sin conseguir estructurar un nuevo ciclo de acumulación que demandase la mano de obra de la región. ${ }^{33}$ En el noroeste la modernización universitaria marcaba un contraste mayor con su medio que en Córdoba o Rosario. En todo el país, estos cambios en la educación y la politización de los alumnos inspiraron críticas conservadoras de las cámaras empresariales que luego honraron los militares instalados en el gobierno tras la asonada de 1966, apoyados en su asalto por un amplio abanico de fuerzas sociales y políticas, y con una considerable acumulación doctrinaria contrainsurgente. ${ }^{34}$

En Brasil, las ideas modernizadoras también adquirieron notoria influencia desde fines de los años '50, motivando grandes desplazamientos territoriales, como la fundación de Brasilia, la nueva capital asentada en una zona de escaso desarrollo, y cierta movilidad social. ${ }^{35}$ La evolución macroeconómica de principios de la década de 1960 estaba signada por la inflación, la crisis de la balanza de pagos y el estancamiento de la actividad industrial. ${ }^{36}$ En este país, carente de la tradición inspirada en la Reforma Universitaria, el golpe de Estado de 1964 clausuró un proceso muy temprano de modernización dentro de carriles similares a los reformistas y subordinó la Universidad al Poder Ejecutivo, dando por tierra la innovadora experiencia de Brasilia aunque sosteniendo algunas intenciones modernizadoras bajo condiciones de autoritarismo.

Ambos países modelos del Estado Burocrático Autoritario, ${ }^{37}$ que durante los primeros años fueron regímenes "no democráticos de capacidad alta", según la tipología de Charles Tilly, es decir sistemas con pocas prácticas prescriptas y toleradas, escasos y violentos conflictos y un gran abanico de

\footnotetext{
33 Cf. Healey, Mark, "El interior en disputa. Proyectos de desarrollo y movimientos de protesta en las regiones extrapampeanas", en James, Daniel (comp.), Nueva Historia Argentina. Violencia, proscripción y autoritarismo (1955-1976), Buenos Aires, Sudamericana, 2007, Tomo IX, pp. 169-212.

34 Cf. Pontotiero, Esteban, "Anticomunismo y catolicismo intransigente en los tempranos años sesenta: la representación de la amenaza revolucionaria en la Universidad Pública. Análisis de documento militar de inteligencia", en Primer Encuentro de Jóvenes Investigadores del Posgrado en Historia e Historia del Arte de IDAES, UNSAM, 2014.

${ }^{35}$ Cf. Aarâo Reis, Daniel, “A vida política”, en Aarâo Reis, Daniel (coord.), Modernizacao, ditadura e democracia 1964-2010, Río de Janeiro, MAPFRE/Objetiva, pp. 75-126.

${ }^{36}$ Cf. Singer, Paul, "O proceso econômico", en Aarâo Reis, Daniel (coord.), Modernizacao, ditadura e democracia 19642010, Río de Janeiro, MAPFRE/Objetiva, pp.183-232.

${ }^{37}$ Cf. O’Donnell, Guillermo, El Estado burocrático autoritario, Buenos Aires, Prometeo, 2009.
} 
acciones prohibidas. ${ }^{38}$ Pese a estas similitudes, las bajas universitarias de la era de Castelo Branco en Brasil fueron notorias pero acotadas, ${ }^{39}$ mientras que las renuncias y cesantías de 1966 y 1967 de la dictadura de Juan Carlos Onganía resultaron en una sangría para el sistema científico argentino, especialmente en la Universidad de Buenos Aires (UBA). ${ }^{40}$

En Perú el golpe de Estado conducido por el general Juan Velasco Alvarado en 1968 presenta notorias diferencias con sus pares sudamericanos. El régimen afectó intereses estadounidenses y de la clase dominante local, sobre todo los terratenientes, perjudicados por la reforma agraria. ${ }^{41}$ Aunque el Gobierno Revolucionario de las Fuerzas Armadas (GRFA) se propuso encuadrar organizaciones sociales y sectoriales en el Estado, no sería correcto considerarlo una dictadura de alta capacidad. La modernización universitaria y la radicalización estudiantil previas habían sido particularmente intensas, ostensible en la elevación exponencial de la matrícula, que pasó a secundar a la Argentina en términos de tasa bruta, en la cantidad de instituciones o en el pasaje de la Federación de Estudiantes Peruanos (FEP) al Frente Estudiantil Revolucionario (FER) como organismo central de los gremios y agrupaciones de alumnos. ${ }^{42}$ En contraste con Argentina y Brasil, inicialmente el gobierno dejó intacta la estructura universitaria, pero en el verano de 1969 estableció una multa muy onerosa para los estudiantes del nivel medio que debían materias del curso anterior. Esta medida despertó grandes protestas en varias ciudades, a las cuales se sumaron los universitarios.

En México, el Partido Revolucionario Institucional (PRI) encabezaba un régimen formalmente democrático de funcionamiento cercano a una dictadura de alta capacidad. La autonomía universitaria existía desde 1929, tras un duro enfrentamiento con el Estado. Como explicó José René Rivas Ontiveros ${ }^{43}$, hasta 1958 los desafíos en este terreno para los gobiernos autodenominados herederos de la Revolución procedían de las derechas, sobre todo de las juventudes del PAN, o de sectores profesionales. Desde aquel año fue creciendo la izquierda:

“... a las posiciones liberales, que en su fachada exterior tendieron a preservar a la Universidad como un santuario de cultura al margen de la política, vienen a sobreponerse las posiciones marxistas y socialistas [...] coincidiendo [...] con otros argumentos de base, en la ruptura tajante entre la Universidad y el Estado y la defensa de la autonomía."44

Esta institución atravesaba un proceso de modernización que la hacía despuntar en un conjunto social donde los logros del llamado "desarrollo estabilizador" comenzaban a encontrar su techo debido, en parte, a que el limitado sistema educativo no podía proveer la cantidad de personal calificado que requerían las nuevas actividades económicas de esta modernización exitosa. ${ }^{45}$ Los ataques de 1968, que motivaron un ciclo de protesta inédito, no fueron los primeros. El 23 de septiembre de 1956 tuvo lugar la Operación P: 1.800 soldados desalojaron el Instituto Politécnico Nacional (IPN), golpearon a los estudiantes y apresaron a los dirigentes de la Federación Nacional de Estudiantes Técnicos (FNET). Los enfrentamientos de 1958 durante la huelga de camiones también mostraron una disposición al ejercicio de la violencia estatal. En 1966 y 1967 se realizaron cercos y balaceras sobre concentraciones estudiantiles en Morelia y Hermosillo, de características similares a la de la Plaza de las Tres Culturas el 2 de octubre de 1968.

\footnotetext{
38 Tilly, Charles, Regimes and repertories, Chicago, UCP, 2006, pp. 80 y ss.

${ }^{39}$ PattoSá Motta, As universidades e o regime militar: cultura política brasileira e modernização autoritaria, Rio de Janeiro, Zahar, 2014, p. 60.

${ }^{40}$ Cf. Buchbinder, Pablo, Historia de las universidades argentinas, Buenos Aires, Sudamericana, 2005.

${ }^{41}$ Cf. Klarén, Peter, Nación y sociedad en la historia del Perú, Lima, IEP, 2004.

${ }^{42}$ Cf. Degregori, Carlos, El surgimiento de..., op. cit. y Lynch, Nicolás, Los jóvenes rojos..., op. cit.

${ }^{43}$ Cf. Rivas Ontiveros, José René, La izquierda estudiantil en la UNAM. Organizaciones, movilizaciones y liderazgos (19581972), México, Porrúa, 2007.

${ }^{44}$ Zermeño, Sergio, México: Una Democracia Utópica. El movimiento estudiantil del 68, Siglo XXI, México D.F., 1978, p. 59.

${ }^{45}$ Cf. Loaeza, Soledad, "Modernización autoritaria a la sombra de la superpotencia, 1944-1968”, en Velázquez García, Erik, et. al., Nueva bistoria general de México, Ciudad de México, El Colegio de México, 2011, pp. 653-698.
} 
En Uruguay el proceso socioeconómico y político de mediados de los años ‘50 estuvo signado por la inflación y el estancamiento de la industrialización sustitutiva, que se remontaba a la crisis de 1929 y había tenido resultados promisorios en el terreno del bienestar popular. ${ }^{46} \mathrm{El}$ sistema político se encontraba en una crisis profunda. Se instauró un mecanismo de gobierno colegiado y, tras largas décadas, en 1958 el Partido Colorado perdió las elecciones a manos del Partido Nacional. El nuevo gobierno firmó un acuerdo con el FMI, contrayendo un inédito empréstito y comenzando reformas liberalizadoras. Los gobiernos subsiguientes, allende los partidos y los cambios constitucionales, puesto que 1966 se estableció un presidencialismo con rasgos autoritarios, alternaron políticas económicas liberales y keynesianas en un contexto signado por la movilización social y la violencia política creciente. ${ }^{47}$ En esta democracia de baja capacidad, que prescribía relativamente pocas prácticas pero que paulatinamente incrementaba el margen de las prohibiciones, se promulgó la autonomía universitaria, tras varios años de reclamos de la única pero gratuita y masiva Universidad de la República (UDELAR). La Ley Orgánica estableció un sistema institucional donde germinaron numerosos proyectos de investigación y publicación ligados a redes científicas trasnacionales y se consolidó una comunidad con especial influencia de las izquierdas, las alas de los grandes partidos y los agrupamientos que formaron FIDEL y luego el Frente Amplio. En esta asincronía entre la política universitaria y la nacional se fue estableciendo una relación conflictiva entre la UDELAR y los distintos gobiernos.

En todos los casos, la "amenaza comunista" fue el motor de las controversias que atravesó la institución universitaria durante el primer lustro de los años '60. Las primeras medidas de las dictaduras y los gobiernos crecientemente autoritarios para refrenar el ascenso estudiantil bregaron por "sacar el agua al pez", es decir, acabar con la autonomía y el cogobierno. Estas iniciativas, a tono con las recomendaciones promovidas desde Estados Unidos por emisarios como Rudolph Atcon, ${ }^{48}$ parecieron exitosas en un primer momento, pero rápidamente se revelaron insuficientes. La capacidad de los movimientos estudiantiles para tejer alianzas con sujetos colectivos más allá de los claustros, centralmente el movimiento obrero, resulta una de las causas del ascenso opositor en el cual los alumnos jugaron un rol destacado y, en algunas circunstancias, como veremos, totalmente decisivo.

En lo que sigue analizamos las estrategias estudiantiles y la identidad política de sus protagonistas con el objetivo de observar las peculiaridades de la acción de los estudiantes argentinos en los años de la revuelta global y latinoamericana. Posteriormente escudriñamos las respuestas de las autoridades universitarias y nacionales ante estos desafíos.

\section{Estrategias estudiantiles}

En la memoria colectiva el año 1968 está marcado por el Mayo Francés. Sin embargo, para el historiador estadounidense Jeffrey Gould las protestas estudiantiles en América Latina, menos recordadas, resultaron más virulentas que las del Primer Mundo, algo observable en su legado de sangre, al tiempo que, como se verá, expusieron una relación más estrecha con la economía y la política nativa. ${ }^{49}$

\section{Río de Janeiro}

\footnotetext{
46 Cf. Yaffe, Jaime, "El proceso económico", en Caetano, Gerardo (dir.), Uruguay. En busca del desarrollo entre el autoritarismo y la democracia. Tomo III - 1930/2010, Montevideo, MAPFRE/Planeta, 2016, pp. 157-201.

${ }^{47}$ Cf. Caetano, Gerardo, "La vida política", en Caetano, Gerardo (dir.), Uruguay. En busca del desarrollo entre el autoritarismo $y$ la democracia. Tomo III - 1930/2010, Montevideo, MAPFRE/Planeta, 2016, pp. 37-111.

48 Atcon, Rudolf, "Las universidades latinoamericanas", ECO, Revista de la cultura de occidente, 1961, vol. VII, pp. 1-169.

${ }^{49}$ Cf. Gould, Jeffrey, "Solidarity under Siege: The Latin American Left, 1968”, American Historical Review, vol. 114, issue 2, 2009, pp. 348-375.
} 
La revuelta latinoamericana de 1968 tuvo como epicentro Río de Janeiro, Montevideo y México. En Brasil, como se comentó, desde 1964 se había instaurado una dictadura militar que anuló la autonomía y el cogobierno de la novel Universidad de Brasilia. ${ }^{50}$ Se desplegaron tropas en los campus, se clausuraron comedores universitarios y los locales de la Unión Nacional de Estudiantes (UNE), que durante los años previos clamaba por una Reforma Universitaria, fueron cerrados u ocupados militarmente.

Como explicó tempranamente Poerner, ${ }^{51}$ el movimiento estudiantil de este país, especial pero no únicamente el carioca, protagonizó decenas de enfrentamientos durante septiembre de 1966, el llamado "septiembre heroico", sin que ese ciclo tuviese una repercusión política nacional. En Argentina, casi al mismo tiempo se desató una oleada estudiantil contra la intervención universitaria, que se agudizó tras el asesinato de Santiago Pampillón en Córdoba, donde las movilizaciones mostraron una radicalidad superior a las de otros puntos del país, cuando los alumnos tomaron las calles, chocaron violentamente con la policía y recibieron el apoyo de contingentes de trabajadores.

En la resistencia estudiantil contra la represión y los acuerdos universitarios con agencias estadounidenses (MEC-USAID) se produjo un ascenso de las corrientes marxistas dentro de la UNE, en detrimento de los católicos de Acción Popular (AP), que a su vez sufrieron desprendimientos radicales. Esto impactó además en un declive del Partido Comunista Brasileño (PCB), siendo relegado por los disidentes de la dirección estadual de Guanabara (DIGB), que pasaron a dirigir União Metropolitana dos Estudantes (UME), los maoístas del Partido Comunista do Brasil (PC do B) y Política Operaria (Polop). ${ }^{52}$

A comienzos de 1968 la dictadura clausuró el comedor Calabouço en Río de Janeiro, motivando numerosas manifestaciones. La similitud con el caso de Corrientes durante mayo de 1969, o de Tucumán a lo largo de los años siguientes, resulta evidente. Sin embargo, las repercusiones de lo ocurrido en la ciudad carioca fueron diferentes. El primer choque letal aconteció el 28 de marzo, cuando fue asesinado Edson Luis de Lima Souto. En respuesta, los estudiantes ocuparon la Asamblea Legislativa estadual y velaron a su compañero envuelto en una bandera de Brasil. Las manifestaciones durante abril y mayo se extendieron a San Pablo, Belo Horizonte, Bahía y Brasilia. El énfasis represivo de la dictadura, de inspiración anticomunista, incluyó la censura a varios políticos del propio régimen y las golpizas a periodistas, que en la capital paulista comenzaron a apoyar al movimiento estudiantil. ${ }^{53}$ Algunos funcionarios y dirigentes propusieron un diálogo con los jóvenes, como el ministro Tarso Dutra, pero en paralelo las manifestaciones eran impedidas por la fuerza. Dentro del movimiento se abrió un largo debate entre las fracciones más proclives al mismo, generalmente aquellas cercanas al catolicismo, que contaron con el apoyo de numerosos docentes y profesionales, y las más refractarias, ancladas en la izquierda radical. Los violentos choques de las primeras semanas de junio tuvieron como vértice la Sexta-feira sagrenta del día 21, cuando fueron detenidos centenares de estudiantes y asesinados 28 manifestantes. Estos eventos tuvieron un hondo impacto sobre el bloque dictatorial, donde el ala dura debió ceder momentáneamente y permitir una manifestación cinco días después, la multitudinaria, popular más que estudiantil, y pacífica Passeata dos Cen Mil.

Mientras en el caso argentino la resistencia estudiantil inicial contribuyó, aún en la soledad, a erosionar a la dictadura desde sus primeros momentos, en Brasil el movimiento estudiantil se convirtió más nítidamente en el canal mediante el cual emergió un amplio descontento con el

\footnotetext{
${ }^{50}$ Cf, Ribeiro Do Valle, María, O diálogo é a violencia. Movimento estudantil e ditadura militar no Brasil, Sao Paulo, UNICAMP, 2008 y PattoSá Motta, Rodrigo, As universidades e..., op. cit.

${ }^{51}$ Cf. Poerner, Arthur, O poder joven..., op. cit.

${ }^{5}$ Cf. González, Juan, "El año breve. Los estudiantes brasileños en su 1968”, en Bonavena, Pablo y Millán, Mariano (eds.), Los '68 latinoamericanos. Movimientos estudiantiles, política y cultura en México, Brasil, Uruguay, Chile, Argentina y Colombia, Buenos Aires, CLACSO-IIGG, 2018, pp. 105-141.

${ }^{53}$ Ribeiro Do Valle, María, O diálogo e..., op. cit., p. 100.
} 
régimen, sobre todo a nivel popular. Como se mencionó, en ambos países la acción estudiantil tras los golpes de Estado sirvió para deslegitimar a los gobiernos de facto, aunque en el caso brasilero, dada la menor organización popular y obrera, el ascenso estudiantil condensó más y mejor el malestar social reinante, mientras que en Argentina las tensiones sociales tendieron a multiplicarse y desde allí converger. Las acciones de los alumnos brasileros abrieron una honda brecha para la protesta frente a un régimen que, hasta el momento, había sufridos escasas manifestaciones opositoras.

El movimiento estudiantil se encontró entonces en el centro de la contienda, habiendo transgredido las formas admitidas por una dictadura de alta capacidad. En ese contexto vivieron un nuevo impulso, en el seno de la UNE, los debates sobre las luchas específicas y la posibilidad de generalizarlas, que enfrentaron a la AP con los grupos de la izquierda radical. Dentro de este sector se ensayaron iniciativas específicas, como el débil Movimento Universidade Crítica, pero la experiencia de los enfrentamientos violentos galvanizó las ideas de muchos militantes guevaristas o maoístas que se enrolaron en organizaciones armadas o, mediante la proletarización, nutrieron una nueva generación de dirigentes obreros. ${ }^{54}$

\section{Montevideo}

Para 1968 en la UDELAR existía una extensa tradición reformista que se remontaba al cogobierno sancionado sesenta años atrás y que había llegado a su consagración jurídica con la autonomía de la Ley Orgánica de $1958 .{ }^{55} \mathrm{La}$ vida política universitaria fue asumiendo el contorno de los debates de la izquierda local, que contaba allí con uno de sus bastiones, y reconociendo tensiones con los distintos gobiernos y figuras políticas de una emergente derecha nacionalista y anticomunista, cuya figura paradigmática fue Benito Nardone. La asincronía entre la política nacional y la universitaria tomó formas extremas para fines de los años '60: mientras en las facultades se confrontaban posiciones en torno a una Reforma de avanzada, como el Plan de Ernesto Maggiolo, rector de esa casa, el sistema político del país experimentaba un giro autoritario y represivo bajo las presidencias de Jorge Pacheco Areco y José María Bordaberry luego, ambos del Partido Colorado.

Las protestas de 1968 en Montevideo comenzaron en mayo, cuando los alumnos de los liceos realizaron sentadas, cortes de calles y ocupaciones de edificios en rechazo del aumento del boleto de ómnibus. Semanas después el gobierno dictó el estado de excepción mediante las Medidas Prontas de Seguridad y el ministro de Educación García Capurro criticó duramente a las autoridades universitarias por permitir las manifestaciones.

Frente a ello, el estudiantado y numerosos contingentes obreros, apoyados por la CNT, continuó movilizado en defensa de las libertades públicas y contra la política económica del gobierno. La capital fue el escenario de centenares de enfrentamientos violentos entre la policía y los activistas, muchas veces en las calles, pero otras en las facultades, que recibieron varias incursiones. Algunos de estos choques dejaron como saldo alumnos o trabajadores heridos de bala, llegando al 14 de agosto cuando fue asesinado Líber Arce, el primero de los tres mártires estudiantiles y comunistas del '68 uruguayo. Tras este proceso se agravó el enfrentamiento entre la UDELAR y el gobierno, rutinizándose una violenta tensión hasta la intervención del 26 de octubre de 1973, que inició el régimen dictatorial en la universidad.

En este ciclo también deben distinguirse estrategias estudiantiles. Las autoridades de la universidad se manifestaron en contra del rumbo autoritario y conservador del gobierno y se solidarizaron con los estudiantes reprimidos, como puede notarse en la Gaceta de la Universidad, publicación oficial de

\footnotetext{
${ }^{54}$ Ridenti, Marcelo, O fantasma da revolucao brasileira, Sao Paulo, UNESP, 2010, p. 129.

${ }^{55}$ Cf. Markarian, Vania, El 68 uruguayo..., op. cit.
} 
la institución. Ese apoyo tenía un contenido democrático y de defensa de la educación pública entendida como un derecho y una herramienta para el bienestar y desarrollo del país.

Por otra parte se encontraba el Partido Comunista (PCU). Desde mediados de los años ' 50 , como puede observarse en su revista Estudios, dedicaba importantes esfuerzos a la política universitaria y a la intelectualidad. Tras la Revolución Cubana alcanzaron la dirección de la Federación de Estudiantes Universitarios del Uruguay (FEUU), en alianza con los socialistas, que coincidían en su apoyo al nuevo régimen de La Habana, y desplazando a los anarquistas. A su vez, desde mediados de los años '60 impulsaron la formación de la Coordinadora de Estudiantes Secundarios del Uruguay (CESU). Mientras la FEUU tenía una larga tradición, reconocida dentro y fuera de los claustros, la CESU era una organización más débil desde todo punto de vista. En el contexto de los enfrentamientos de 1968 el PCU apoyó a Maggiolo, reelecto por unanimidad, esgrimiendo la "unidad reformista" frente al ataque del gobierno, sin avalar al plan de Reforma del año anterior, considerado como "ilusiones desarrollistas".

En este sentido, puede notarse que en el caso uruguayo existe una disposición de las fuerzas completamente diferente a la de Brasil y Argentina, donde la universidad ya había sido intervenida y sus acciones institucionales eran contrarias a las movilizaciones. Asimismo, en Montevideo tuvo lugar una alianza más estrecha con los trabajadores que en Río de Janeiro, donde no se cuenta una central gremial en las manifestaciones, pero menos radical que en los "azos" de Córdoba, Rosario o Tucumán, donde las ciudades quedaron momentáneamente bajo control obrero-estudiantil.

El tercer sector estudiantil del ' 68 uruguayo lo constituye una amplia base juvenil que se sumó a la militancia en aquel contexto, cuestionó las formas organizativas y promovió instancias menos institucionalizadas y más cercanas a la democracia directa, como las asambleas. Esta corriente del movimiento tuvo un gran peso entre los secundarios, perdiendo la CESU su rol dirigente, aunque fue algo menos decisiva en la UDELAR, donde el ciclo de enfrentamientos se prolongó.

Desde esta base juvenil surgieron organizaciones radicalizadas de distintas orientaciones de izquierda, como el Frente Estudiantil Revolucionario (FER), el colectivo Resistencia Obrero Estudiantil (ROE), en un intento de continuidad de la proscrita Federación Anarquista Uruguaya (FAU) y los Grupos de Acción Unificadora (GAU), integrado por católicos de izquierda. También muchos jóvenes se incorporaron al ascendente Movimiento de Liberación Nacional Tupamaros. Sin embargo, como explicó Markarian, las fronteras entre las izquierdas tenían cierto grado de fluidez. Los estudiantes del PCU mostraron una afinidad notoria con las ideas y símbolos de la llamada "nueva izquierda", al tiempo que sus filas se multiplicaban.

\section{Ciudad de México}

Durante ese año la Ciudad de México fue escenario de grandes conflictos estudiantiles, precedidos de otros ocurridos en estados como Michoacán o Sonora. ${ }^{56}$ El 26 de julio de 1968 dos manifestaciones terminaron en duros enfrentamientos con el cuerpo de Granaderos. La primera de alumnos de preparatorias que protestaban por los abusos policiales de días atrás, en el contexto de enfrentamientos pandilleros entre jóvenes. La segunda, en homenaje a la toma del Moncada, que fue engrosada por personas de la movilización anterior. Estos hechos motivaron protestas de grupos estudiantiles que denunciaron al PRI, a las organizaciones porriles como el Movimiento Universitario de Renovada Orientación (MURO) y a las fuerzas de seguridad con las cuales protagonizaron durante el ' 68 mexicano centenares de enfrentamientos violentos, sufriendo miles de detenciones. Días después, el 30 de julio, el Ejército tomó por la fuerza el Colegio San Ildelfonso y destruyó su antiquísima puerta, haciendo más de 1.000 prisioneros y lesionando a 400 alumnos.

\footnotetext{
${ }^{56}$ Cf. Ramírez, Ramón, El movimiento estudiantil..., op. cit.; Zermeño, Sergio, México una democracia..., op. cit. y Rivas Ontiveros, José René, La izquierda estudiantil..., op. cit.
} 
El gobierno afirmaba que el Partido Comunista Mexicano (PCM) instrumentaba a los estudiantes para boicotear los Juegos Olímpicos que se realizarían ese año en la capital del país. ${ }^{57}$

En el IPN y en la Universidad Nacional Autónoma de México (UNAM) creció la indignación. En la Ciudad Universitaria (CU) se izó la bandera a media asta. El rector Javier Barros Sierra pronunció un discurso en defensa de la autonomía y encabezó una movilización. El 2 de agosto se concentraron 100.000 personas en el Zócalo. Días después, los principales dirigentes estudiantiles consensuaron un petitorio. ${ }^{58}$

Al compás de la agitación se formó el Consejo Nacional de Huelga $(\mathrm{CNH})$, con integrantes elegidos por asambleas de sus centros educativos. En su debut como convocante, el 13 de agosto reunió 150.000 personas frente al Palacio Nacional. Casi inmediatamente organizó grupos de brigadistas para conseguir la solidaridad de la población, principalmente de la clase trabajadora, cuyos sindicatos estaban encuadrados en el partido que controlaba el régimen. Una posición diferente presentaba el magisterio y los grupos de profesores, quienes el 20 de agosto se movilizaron en decenas de miles hacia el Zócalo para apoyar a los estudiantes.

Una semana después, con la solidaridad de los médicos del Hospital General y el paro petrolero, una concentración izó la bandera del $\mathrm{CNH}$ frente al Palacio Nacional. No obstante la gran concurrencia, fueron desalojados mediante un gran despliegue militar que duró casi toda la noche. Al día siguiente, el gobierno organizó un acto de "desagravio a la bandera", contando con participación de la Confederación de Trabajadores Mexicanos (CTM). Luego, el 2 de septiembre, la CTM afirmó que "No existe un problema estudiantil real" y calificó al movimiento como "subversivo". 59

En este punto subrayamos dos diferencias del caso mexicano con el de Brasil, Uruguay y Argentina. La primera es que el organismo que conducía al movimiento estudiantil había sido creado en el mismo proceso, mientras que la UNE, la FEUU y la FUA contaban con una larga trayectoria. La segunda es la relación con los trabajadores. En la experiencia carioca los sindicatos no estaban articulados orgánicamente al régimen dictatorial, en Montevideo la CNT y varios grupos de base apoyaron a los estudiantes, mientras que en Córdoba, Rosario y Tucumán los azos fueron revueltas obrero-estudiantiles.

Las manifestaciones estudiantiles de la primera mitad de septiembre prolongaron las consignas cívicas. La "Marcha del Silencio" del 13 de septiembre, similar a la Marcha del Silencio de Rosario en mayo del año siguiente, expresaba un repudio al autoritarismo y la elusión de definiciones aunaba el malestar de amplios sectores. Días después, el profesor y militante socialista Heberto Castillo dio el tradicional grito de la Independencia en la CU. Las similitudes con las marchas argentinas de mayo de 1969, con las banderas con el crespón negro en luto por el asesinato de los estudiantes, o con el funeral de Edson Luis en Río de Janeiro, con sus restos cubiertos por la insignia nacional, resultan evidentes.

Poco después, el 18 de septiembre el Ejército ocupó la CU y en jornadas subsiguientes el IPN, donde los estudiantes resistieron durante horas, corrió la misma suerte. El rector Barros Sierra renunció en protesta. El movimiento ingresó en una nueva etapa, la presión militar hacía

\footnotetext{
${ }^{57}$ Décadas después se confirmó que los “infiltrados” eran el presidente Gustavo Díaz Ordaz y el secretario de la Gobernación Luis Echeverría Álvarez (responsable de la seguridad) que se desempeñaban como informantes de la CIA. Aguayo, Sergio, El 68. Los estudiantes, el presidente y la CLA. Ciudad de México, Proceso, 2018.

${ }^{58}$ El pliego elevado reclamaba: 1) Libertad a los presos políticos; 2) Destitución del jefe de la policía capitalina Luis Cueto Ramírez; 3) Desaparición del cuerpo de granaderos, corporación utilizada permanentemente para intimidar y reprimir las protestas sociales; 4) Derogación del artículo 145 y 145 bis del Código Penal, que restringían las libertades democráticas; 5) Indemnización a las familias de los muertos y heridos; 6) Aclaración de las responsabilidades de las autoridades, la policía, los granaderos y el ejército en los actos de represión y vandalismo. Zermeño, Sergio, México una democracia..., op. cit., p. 29.

${ }^{59}$ Ramírez, Ramón, El movimiento estudiantil..., op. cit., p. 288.
} 
impensable un diálogo. El 2 de octubre el gobierno llevó adelante una violenta represión contra un mitin estudiantil en la Plaza de las Tres Culturas, adyacente a la Cancillería, cuyo número de víctimas fatales aún es objeto de controversia. La Masacre de Tlatelolco, así se la conoció, y los masivos y prolongados encarcelamientos comenzaron a cerrar un ciclo de movilizaciones estudiantiles y populares inéditas en el México posterior a la Revolución. Al igual que en Brasil, el movimiento estudiantil fue el canal por el cual emergió un descontento amplio y anteriormente soterrado.

En este proceso convivieron tres corrientes universitarias, como señaló Sergio Zermeño, el "sector politizado de izquierda", identificado con el PCM y otras agrupaciones socialistas aliadas; el "sector profesionista", cercano a la posición rectoral, y la "base estudiantil radical joven", surgida en el conflicto, la cual, al igual que en Uruguay, adoptó las modalidades organizativas de la democracia directa y formó, o se sumó, a las corrientes de la izquierda radical ya existentes, donde tuvieron especial influencia las ideas maoístas, castro-guevaristas, consejistas y, en menor medida, trotskystas. ${ }^{60}$ Esta evolución representaba el punto de llegada de una década de ascenso de la izquierda en la UNAM. ${ }^{61}$

\section{Ayacucho}

Las revueltas estudiantiles-populares de mayor repercusión en la historia reciente de Perú ocurrieron durante junio de 1969 en Ayacucho y Huanta, contra las multas del gobierno de Velasco Alvarado a los alumnos secundarios que habían suspendido materias del curso anterior. Hacia los años '60 Perú era uno de los países más pobres del continente y su sistema de partidos atravesaba una crisis severa. El apoyo a liberales o conservadores de la Alianza Popular Revolucionaria Americana (APRA), surgida la Reforma, la condujo a una mengua de su influencia en el mundo estudiantil. La otra formación nacida en aquel proceso, el Partido Comunista Peruano (PCP), sufrió dos escisiones maoístas: en 1964 el PCP-Bandera Roja (BR) y en 1968 el PCP-Patria Roja (PR). El APRA fue desplazado por el PC en la conducción de la Federación de Estudiantes Peruanos (FEP), organismo que fue perdiendo importancia a medida que crecía el FER, inicialmente comandado por el PCP, luego en manos del PCP-BR y, desde 1970, del PCP-PR.

Durante este período se reabrió la Universidad Nacional de San Cristóbal de Huamanga (UNSCH) en Ayacucho. Inicialmente bien financiada y con ímpetu modernizante, convocó numerosos profesores e investigadores. Esto la convirtió en una institución desfasada de su contexto local, caracterizado por la prolongada decadencia, casi terminal, de una estructura agraria latifundista, de terratenientes que fueron perdiendo peso en la élite del país y de campesinos empobrecidos.

Esta casa de estudios recibió una gran cantidad de estudiantes, multiplicando por 20 su matrícula entre 1960 y $1980 .^{62}$ Durante los primeros años la aristocracia local albergó expectativas respecto de la universidad. Prontamente la democratización en el acceso a la educación superior y el arribo de personal de izquierdas colocó frente a frente a la UNSCH y a la clase dominante local, donde la Iglesia Católica cumplía un rol de articulación fundamental. Tal vez el ejemplo más agudo de ese distanciamiento lo constituya el núcleo del PCP-BR, conducido por un profesor universitario de Filosofía proveniente de Arequipa, Abimael Guzmán, que a finales de los años '60 conformó el PCP Sendero Luminoso (PCP-SL).

Los primeros protagonistas del "movimiento por la gratuidad de la enseñanza" de junio de 1969 fueron los estudiantes secundarios de Huanta, apoyados por sus familias y por el sindicato docente. Conformaron el Frente Único de Estudiantes de Huanta (FUEH) y expandieron la huelga por varios departamentos de la sierra. Días después se erigió una organización homónima en Ayacucho, el Frente Único de Estudiantes Secundarios de Ayacucho (FUESA). Las primeras manifestaciones

\footnotetext{
${ }^{60}$ Zermeño, Sergio, México una democracia..., op. cit., pp. 36 y ss.

${ }^{61}$ Cf. Rivas Ontiveros, José René, La izquierda estudiantil..., op. cit.

${ }^{62}$ Cf. Degregori, Carlos, El surgimiento de..., op. cit.
} 
callejeras resultaron reprimidas por la policía con armas de fuego y los grupos movilizados se acercaron al local del Frente de Defensa del Pueblo de Ayacucho (FDPA), una entidad que articulaba a las organizaciones populares de la ciudad, donde se afiliaron el FUEH y el FUESA.

Tras una semana de choques en ambas ciudades, durante la mañana del 21 de junio fueron apresados numerosos dirigentes, entre ellos el mencionado Guzmán. En Ayacucho, desde las 7, se formaron columnas de manifestantes que organizaron grupos de autodefensa. Según las autoridades murieron cuatro personas, "Los heridos de gravedad son trasladados a [...] Lima, controlados por la policía. [...] se rumorea que son muchos los desaparecidos." ${ }^{63} \mathrm{Al}$ día siguiente llegaron columnas campesinas a Huanta. Junto a los estudiantes tomaron las calles y ocuparon los puestos de la Guardia Civil y la Policía de Investigaciones. La multitud empujó a la Guardia Civil hacia la Plaza de Armas, donde horas después comenzó un tiroteo desde los altos de los edificios. Las masas reunidas allí fueron dispersadas por los sinchis, una unidad militarizada de paracaidistas de la Policía Nacional. Oficialmente fueron 14 muertos, "Pero pobladores aseguran haber visto a [...] la noche a policías [...] recogiendo muertos y heridos valiéndose de ponchos [...] En una esquina el carro basurero recibía los cadáveres." ${ }^{64}$

Al día siguiente toda la zona fue militarizada e incomunicada. El gobierno denunció la agitación como producto de los rumores de una reforma agraria, al tiempo que responsabilizó a los "provocadores" y "extremistas". El empresariado denunció la subversión y el propio PCP, que apoyaba a Velasco Alvarado, tildó la revuelta de movida conjunta del "APRA, la CIA y las direcciones aventureras de $[\ldots]$ los desclasados grupos 'chinos'...". 65

\section{Córdoba, Rosario y Tucumán $n^{66}$}

En este contexto mundial y regional, durante 1968 el gobierno argentino se contentaba por la calma de los alumnos del país. ${ }^{67}$ Una primera evidencia de que esa confianza era desmesurada la ofrecieron las luchas estudiantiles de mediados de ese año para conmemorar el cincuentenario de la Reforma Universitaria. ${ }^{68}$ Estas movilizaciones, que derivaron en fuertes enfrentamientos con la policía, mostraron un primer conato de recuperación militante tras la derrota sufrida con la intervención universitaria de 1966.

Que esa confianza gubernamental no era adecuada, lo ratificaron los sucesos de mayo de 1969. Primero en Corrientes y Chaco, después en Rosario y Tucumán, y finalmente en Córdoba, emergió un movimiento de protesta donde estudiantes y obreros jugaron un papel protagónico. El Cordobazo dio nombre al período, pero ese sufijo también le cupo a experiencias posteriores, de acuerdo a un estudio reciente no menos de $37 .^{69}$

Para entender el ascenso estudiantil fueron centrales, además de los anteriores levantamientos, el Rosariazo de septiembre de 1969, el Viborazo cordobés de marzo de 1971 y, sobre todo, los

\footnotetext{
${ }^{63}$ Degregori, Carlos, El surgimiento de..., op. cit., p. 63.

${ }^{64}$ Degregori, Carlos, El surgimiento de..., op. cit., p. 65.

${ }^{65}$ Degregori, Carlos, El surgimiento de..., op. cit., p. 67.

${ }^{66}$ Algunos trabajos clásicos sobres los "azos" de estas ciudades: Balvé, Beba, et. al., Lucha de calles lucha de clases: elementos para su análisis: Córdoba 1971-1969, Buenos Aires, CICSO/RyR, 2005; Balvé, Beba y Balvé, Beatriz, El '69: huelga política de masas: Rosariazo, Cordobazo, Rosariazo, Buenos Aires, CICSO/RyR, 2005; Brennan, James, El Cordobazo: las guerras obreras en Córdoba, 1955-1976, Buenos Aires, Sudamericana, 1996; Gordillo, Mónica, Córdoba en los '60, Córdoba, UNC, 1999 o Crenzel, Emilio, El Tucumanazo, Tucumán, UNT, 1997.

${ }^{67}$ Cf. Potash, Robert, El ejército y la política en la Argentina. 3: 1962-1973: de la caída de Frondizi a la restauración peronista; segunda parte, 1966-1973, Buenos Aires, Sudamericana, 1994.

${ }^{68}$ Cf. Bonavena, Pablo y Califa, Juan Sebastián, "El '68 argentino. Luchas estudiantiles en los albores de un ascenso de masas”, en Bonavena, Pablo y Millán, Mariano (eds.). El 68 latinoamericano. A 50 años de Tlatelolco. Movimientos estudiantiles, política, cultura, historia y memoria, Buenos Aires, CLACSO, 2018, pp. 201-232.

${ }^{69}$ Cf. Fernández, Juan, et. al., "Aportes para el estudio de los levantamientos de masas en Argentina entre 1968 y 1974 ”, ponencia en las VII Jornadas de Jóvenes Investigadores del Instituto de Investigaciones Gino Germani. Noviembre de 2013.
} 
Tucumanazos de noviembre de 1970 y junio de 1972. En estas tres ciudades existían activas estructuras organizativas de la clase trabajadora, con tradiciones clasistas. Al mismo tiempo, se alojaban universidades que estaban entre las más pobladas del país, con extensas trayectorias militantes reformistas encarnadas en centros, federaciones y variadas agrupaciones (los comunistas del Movimiento de Orientación Reformista, los socialistas del Movimiento Nacional Reformista, los radicales de Franja Morada o la izquierda nacional de la Agrupación Universitaria Nacional), los peronistas alejados de esas estructuras y recreados en un sinfín de pequeños grupos que se armaban y disolvían para rearmarse de nuevo (el Frente Estudiantil Nacional, oriundo del reformismo y la izquierda, se destacaba por su volumen y mayor organización), con activismo católico en pleno giro tercermundista y peronista (Integralismo, Ateneo) y también con la emergencia de grupos de izquierda maoísta (el Frente de Agrupaciones de Izquierda o la Tendencia Universitaria Nacional Antiimperialista Combatiente), trotskista (la Tendencia Estudiantil Revolucionaria Socialista y la Tendencia de Agrupaciones Estudiantiles de Avanzada) o guevaristas dentro del reformismo y en ocasiones más allá del mismo (los Grupos de Base cordobeses o la Tendencia Antiimperialista Revolucionaria). Al calor de estos acontecimientos, que encontraron parangón por el lado de la acción estudiantil en otras universidades como la UBA, pero no gozaron con el mismo acompañamiento del movimiento obrero, los alumnos aparecieron como un sujeto peligroso para la burguesía que buscaba reordenar el país.

San Miguel de Tucumán fue centro de la mayor conflictividad con tres grandes movimientos de masas en ese ciclo. A diferencia de Córdoba y Rosario, aquí no hubo una industrialización vigorosa en la etapa previa que transformase la sociabilidad urbana. Más bien, lo que sucedió fue la desarticulación de una estructura relativamente atrasada, signada por el cierre de los ingenios azucareros que dispuso la dictadura en su fallida iniciativa desarrollista. Los padecimientos que debieron atravesar los trabajadores de la provincia reforzaron aún más la alianza popular en que se inscribió el movimiento tucumano.

A contramano de lo que suele sostenerse, en nuestra investigación pudimos constatar que el diverso pero relativamente centralizado reformismo descripto anteriormente fue el bloque que protagonizó la mayor cantidad de acciones en los tres lugares entre 1969 y 1972, y no sólo allí. ${ }^{70}$ Cuando desagregamos los datos, las cifras arrojan que en Rosario la cantidad de acciones de este actor es mayor, seguido por Córdoba y finalmente Tucumán. En esta última provincia la izquierda radical, no reformista pero tributaria de varias ideas legadas de la tradición inspirada en la Reforma de 1918, se coloca ligeramente a la cabeza de la lucha. El tándem de catolicismo y peronismo, por su parte, queda muy por detrás en las tres provincias.

Como se observa, donde el impacto del desarrollismo fue mínimo y la Universidad jugó un papel modernizante en relación a su sociedad, siendo mayor la distancia sociedad/universidad, al tiempo que la descomposición social que ocasionó la dictadura se agudizó, se impuso la izquierda radical y sus formas de acción más belicosas. Por eso, sostenemos que la situación tucumana es más parecida a la de Ayacucho, mientras que la de Córdoba y Rosario se asemeja a la de Montevideo y Ciudad de México. Sin embargo, la completa ausencia en Argentina de democracia formal, ubica a la situación en ese aspecto más lindante a la brasileña, aunque en nuestro país la capacidad de esta dictadura fue menor que en esa nación. En buena medida ello fue fruto de su incapacidad para recuperarse del golpe asestado por tales confrontaciones.

En definitiva, visto desde nuestro país, la situación tucumana es singular, alejándose mucho más de la de Córdoba y Rosario, manifestaciones más acordes a los parámetros característicos que este proceso asumió en las sociedades urbanas Latinoamericanas impactadas por el desarrollismo. El gráfico que sigue brinda una síntesis de lo explicado en este apartado.

\footnotetext{
${ }^{70}$ Califa, Juan Sebastián y Millán, Mariano, “La lucha estudiantil durante los 'azos’. Cordoba, Rosario y Tucumán en perspectiva comparada, 1968-1972, Conflicto Social, vol. 12, núm. 22, Buenos Aires, IIGG-UBA (en prensa: diciembre de 2019).
} 


\section{Gráfico $\mathrm{n}^{0} 1$}

Ciudades latinoamericanas que fueron escenario de revueltas urbanas con participación estudiantil a fines de los años ' 60 y principios de los ' 70 , ordenadas según grado de articulación de los proyectos desarrollistas, modernidad relativa de la universidad respecto a su medio y tipo de régimen político

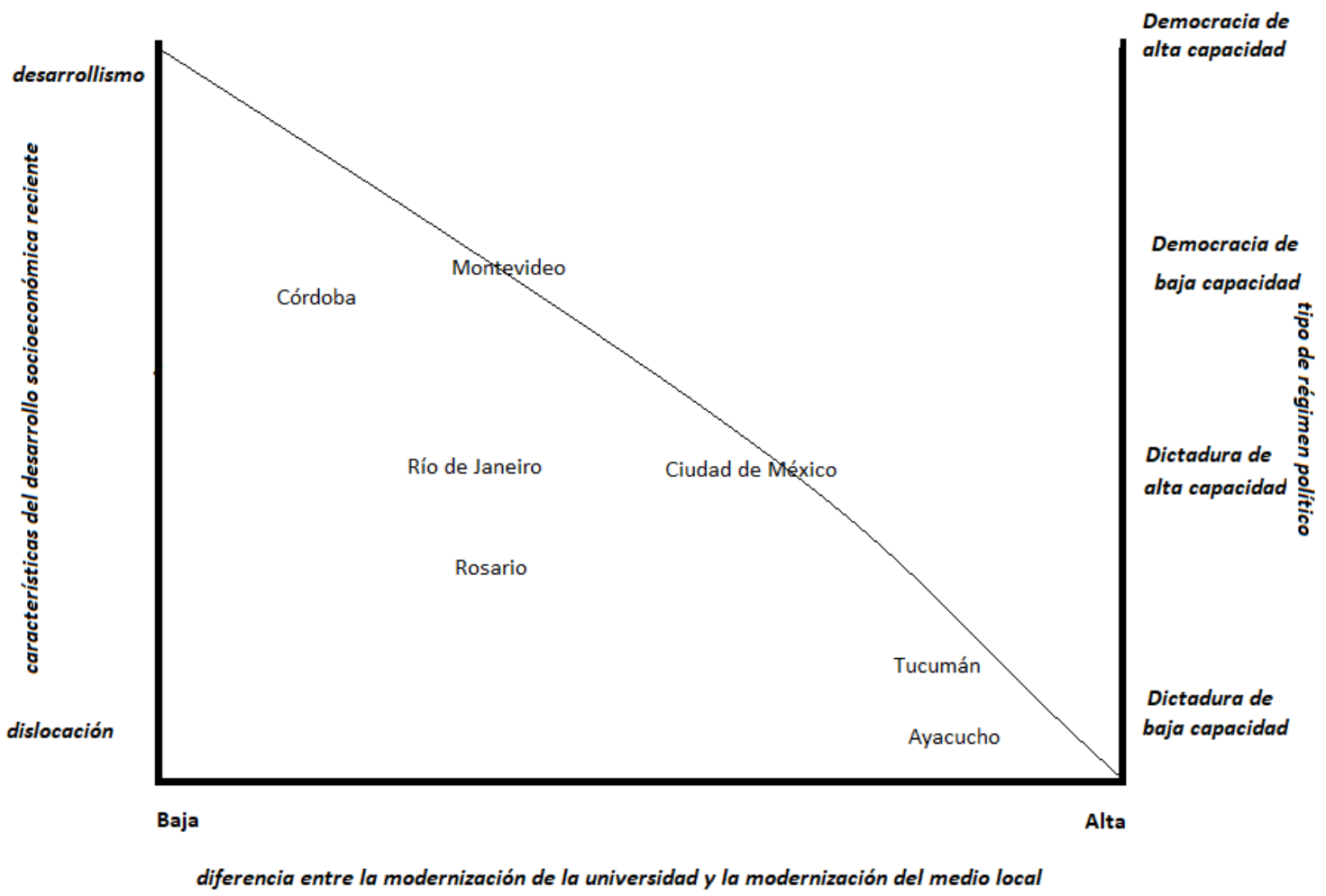

\section{Consecuencias universitarias y políticas del auge estudiantil}

Un diagnóstico, común tras el ciclo analizado, sostenía que la universidad latinoamericana, y también la de otras latitudes, se encontraba en crisis. Esta situación era manifestación de una crisis social más amplia, pero la Universidad podía, y debía, intervenir en su solución transformándose, como afirmaron los ex rectores de la Universidad de Brasilia, Darcy Ribeiro, ${ }^{71}$ y de Buenos Aires, Risieri Frondizi, ${ }^{72}$ por citar dos figuras señeras del proceso de modernización.

En este nuevo clima, los gobiernos de la región revisaron sus estrategias universitarias, o quizás, se aprestaron a elaborar una. Su objetivo inmediato no apuntaba a una revisión global de la universidad y sus desafíos intelectuales, sino a la tarea apremiante de contener el alza estudiantil.

En un primer momento, en las filas gubernamentales se vivió una etapa de zozobra cuando se comprobó que el problema no se solucionaba con una represión frontal en las calles y un poco de tiempo para que las cosas se acomodaran. Allende los matices, advertimos dos grandes posturas:

\footnotetext{
71 Cf. Ribeiro, Darcy, La Universidad Latinoamericana, Caracas, Editorial de la Biblioteca Universidad Central de Venezuela, 1971.

${ }^{2}$ Cf. Frondizi, Risieri, La Universidad en un mundo de tensiones: misión de las universidades en América Latina, Buenos Aires, Paidós, 1971.
} 
reabrir el diálogo para ganar tiempo y aislar al sector más radicalizado de la base estudiantil o ejercer a una represión más cruda sin perder el tiempo. A pesar de las obvias diferencias, no se trataba de posturas antagónicas. Ambas se proponían derrotar la movilización estudiantil radical, distanciando a la vanguardia de la base. Asimismo, en los hechos se complementaron, aunque el modo que esta suma se efectuó se corresponde con el desarrollo de los movimientos estudiantiles en cada país.

La dictadura brasileña respondió a la oleada de movilización estudiantil incrementando sus rasgos represivos mediante el Acto Institucional $\mathrm{n}^{\circ} 5$. La depuración de los planteles docentes y estudiantiles de 1969 fue mucho más significativa que la de 1964. Presentó un notorio sesgo anticomunista, aunque sus magnitudes crecieron también por las rivalidades en los campus. En este país el movimiento estudiantil contó con escaso apoyo del movimiento obrero. Las luchas del '68 en Río de Janeiro canalizaron descontentos amplios, pero casi sin definiciones clasistas. Las causas se encuentran en la dinámica del movimiento laboral local, menos disruptivo por entonces que el de otras latitudes. Frente a ello, la dictadura profundizó sus rasgos autoritarios al tiempo que su política universitaria recuperó, en buena medida, el lugar asignado a la ciencia durante la etapa democrática, una diferencia sustancial con lo acaecido en Argentina. Bajo la sombra de una amplia y articulada red de espionaje en las facultades, se crearon numerosos cargos de dedicación exclusiva, se financió la actividad científica, se abrieron posgrados, se otorgaron becas, entre otras medidas. Amén de las múltiples causas, el rápido éxito represivo sentó condiciones favorables para la modernización autoritaria.

En el caso uruguayo, durante la deriva autoritaria del régimen el gobierno y las organizaciones de la derecha incrementaron su hostilidad hacia la Universidad. Sin embargo, la mayor tradición democrática e igualitaria del país, junto a la relativa solidez de las alianzas del movimiento estudiantil con el muy organizado movimiento obrero, ralentizaron la ofensiva contra la UDELAR hasta 1973. $\mathrm{Al}$ mismo tiempo, si bien pudo entreverse un conflicto generacional en la Universidad, en sintonía con lo sucedido en otros países, ${ }^{73}$ no es menos cierto que la relación entre las autoridades universitarias y los estudiantes era menos tensa que en las naciones vecinas. La "unidad reformista", utilizando palabras del PCU, constituía un escudo protector de los estudiantes.

El caso mexicano representa otro ejemplo de cierta cordialidad entre estudiantes y autoridades, como en la UNAM del rector Barros Sierra. Durante el sexenio del presidente Gustavo Díaz Ordaz el hasta entonces incontestado régimen priísta respondió al desafío estudiantil con una escalada represiva de una magnitud casi sin ejemplos en el mundo. Después de esta labor, cubierta por la inmunidad judicial, y en el marco de la derrota de la vanguardia radicalizada, el nuevo gobierno de Luis Echeverría Álvarez buscó una concertación con varios grupos estudiantiles, en sintonía con la política reformista y modernizadora del nuevo rector Pablo González Casanova en la UNAM. Sin embargo, cuando el movimiento estudiantil retornó a las calles a principios de la década siguiente, el gobierno no dudó en recurrir a la coerción estatal y paraestatal que, si bien no dejó el tendal de muertes de la Masacre de Tlatelolco, demostró que esa posibilidad estaba latente.

Poco después de reprimir duramente el movimiento por la gratuidad de la enseñanza, la dictadura de Perú se propuso encuadrar las organizaciones sociales, intentando articular demandas sectoriales y apoyo popular en el Sistema Nacional de Apoyo a la Movilización Social (SINAMOS). Aquellas jornadas en la sierra y esta iniciativa, en un ambiente universitario donde los partidos tradicionales carecían de predicamento, contribuyeron a la consolidación de la hegemonía de las fuerzas maoístas "antifascistas" durante dos décadas. En este conjunto se destaca el PCP-SL, un agrupamiento pequeño en 1969, pero influyente en los sucesos de Ayacucho, que fue tomando control de aspectos clave de la UNSCH, como el bienestar estudiantil y, luego, los concursos docentes. En 1972 el gobierno de Perú ensayó una reforma universitaria que otorgó voz y voto a los estudiantes a cambio de un nuevo sistema académico. El PCP-BR y el PCP-PR participaron de los nuevos organismos, cuyo funcionamiento distó de ser pacífico y de institucionalizar un nuevo orden. Algo

\footnotetext{
${ }^{73}$ Cf. Markarian, Vania, El 68 uruguayo..., op. cit.
} 
similar ocurrió en Ayacucho con la reforma agraria, que desarticuló los mecanismos tradicionales de autoridad en un medio donde el campesinado ya se había movilizado junto a los estudiantes. Esta convergencia se encuentra en el centro de las explicaciones sobre la insurgencia senderista.

A la luz de estos casos, recorridos de modo conciso, nos interesa echar luz sobre la singularidad argentina. Como se vio, en nuestro país los "azos" con centro en las ciudades del interior, no concluyeron con una derrota para los estudiantes, sino para el régimen. Además, la alianza en las calles con el movimiento obrero, un sector más y mejor organizado que en otros países del continente, fue una conquista insoslayable del proceso estudiantil. Es una peculiaridad del caso argentino que la dictadura haya sido derrotada al punto de tener que marcharse convocando a elecciones.

Sin embargo, si observamos el ciclo de movilización, resulta convergente con su periplo mundial. Así, en 1972 descendieron pronunciadamente los enfrentamientos sociales que protagonizó el estudiantado argentino, más abruptamente si se observa la acción directa con violencia. ${ }^{74} \mathrm{El} \mathrm{ciclo}$ radical, visto desde el ángulo de las movilizaciones, duró lo mismo que en otras latitudes, aunque el clima de victoria pareció extenderlo aquí.

En el ínterin, la dictadura argentina debió flexibilizar su política hacia la Universidad, con especial atención a los estudiantes. Al tiempo que se ejerció una represión más selectiva, preventiva y con crecientes rasgos de clandestinidad, la política universitaria tuvo que abrirse a las demandas estudiantiles. ${ }^{75}$ En este escenario, se conquistó un mayor acceso a las casas de estudios, dando por tierra con los cupos de ingreso. ${ }^{76}$

De acuerdo a su diagnóstico más general de la sociedad argentina, la gran burguesía y el partido militar que la expresaba tenían un dilema de timing. Precisaban perfeccionar y agilizar sus prácticas represivas, pero el contexto lo impedía. Esto resultó evidente en los acontecimientos criminales de Trelew, que constituyeron un ensayo general de lo que vendría, pero mostraron la inviabilidad política de ese tipo de acciones en esa coyuntura. Para avanzar en este sentido en el terreno universitario el requisito era maniatar las energías estudiantiles.

El camino hacia la destrucción de esta desafiante alianza obrero-estudiantil no estuvo exento de escollos, como lo evidenció el Quintazo tucumano de 1972. No obstante, ese caso fue la excepción dentro de un proceso de declive pronunciado de la movilización estudiantil a nivel nacional. ${ }^{77} \mathrm{En}$ Rosario y Córdoba, sede de otros dos grandes movimientos estudiantiles de masas que derivaron en "azos", las aguas se aquietaron a la espera de las urnas. ${ }^{78}$

Posteriormente, durante el tercer peronismo no se registraron nuevos levantamientos estudiantiles. Los "azos" de aquella etapa etiquetaron, generalmente, ataques de la derecha sobre las fuerzas populares. Los estudiantes prosiguieron su militancia universitaria con un inédito respeto a la institucionalidad, algo observable en el predominio, desde 1973, de las declaraciones de apoyo al

\footnotetext{
${ }^{74}$ Cf. Califa, Juan Sebastián y Millán, Mariano, "Un abordaje cuantitativo de las luchas del movimiento estudiantil de Córdoba entre 1966 y 1976", ponencia en las Jornadas a 50 años del Cordobazo, Facultad de Filosofía y Humanidades, Universidad Nacional de Córdoba, mayo de 2019.

${ }^{75}$ Cf. Califa, Juan y Millán, Mariano, "La represión a las universidades y al movimiento estudiantil argentino entre los golpes de Estado de 1966 y 1976”, HIb, vol. 9, núm. 2, 2016, pp. 10 - 38.

${ }^{76}$ Cf. Califa, Juan Sebastián y Seia, Guadalupe, "La ampliación del sistema universitario argentino durante la 'Revolución Argentina'. Un estudio de sus causas a través del caso de la Universidad de Buenos Aires (1969-1973)”, A Contracorriente, vol. 15, núm. 1, 2017, pp. 36-59.

77 Inés Izaguirre contabilizó cinco "azos" en el país durante 1972. (abril: "Mendozazo"; junio: "Quintazo" o $2^{\circ}$ "Tucumanazo"; julio: "Malargüinazo"; julio: "Rocazo"; octubre: "Trelewlazo"). "El mapa social del genocidio", en Izaguirre (y cols.). Lucha de clases, guerra civil y genocidio en la Argentina, 1973-1983. Antecedentes. Desarrollo. Complicidades, Buenos Aires, Eudeba, 2009, pp. 73-117, p. 91.

${ }^{78}$ Cf. Izaguirre, Inés, "El mapa social...”, op. cit., y Millán, Mariano, "Las luchas del movimiento estudiantil rosarino del Cordobazo a la «Primavera Camporista» (1969 - 1973)”, Archivos del movimiento obrero y la izquierda, núm. 10, 2017, pp. 141-161.
} 
gobierno o a las autoridades por sobre la acción directa y la movilización callejera. ${ }^{79}$ En este contexto se incrementó notoriamente la influencia de la izquierda del peronismo, particularmente en la UBA, aunque esas organizaciones no pudieron estabilizar esa acumulación. En 1974, en un contexto de represión paraestatal, empezaron su franca retirada, algo que también experimentaron luego otras fuerzas de izquierda y del reformismo, todos muy fraccionados en líneas de acción que en la dinámica del proceso se iban colocando más o menos a la izquierda, dando lugar incluso a alianzas que poco tiempo atrás hubieran resultado insólitas. Es un dato relevante que retrata el nuevo panorama el hecho de que la resistencia callejera y fabril de la clase obrera ante la política económica del ministro Celestino Rodrigo durante 1975 -el llamado "Rodrigazo"-, no contó con respaldo activo del movimiento estudiantil, ya muy desarticulado. Así, una etapa de movilización y lucha estudiantil, la más importante de la historia argentina, se había clausurado definitivamente.

\section{Conclusiones}

El proceso estudiantil argentino acaecido entre fines de los años sesenta y principios de los setenta integra un ciclo mundial de movilización juvenil. Como tal, duró aproximadamente lo mismo que en otras latitudes. La masificación de los sistemas universitarios, el descenso del ciclo expansivo del capitalismo de posguerra, así como el cambio de su base tecnológica que otorgaba a los jóvenes un lugar privilegiado en la producción y en el consumo, suelen enumerarse para explicar el ascenso estudiantil.

Para los países occidentales también se pone énfasis en el opresivo control que empezó a recaer en las generaciones lozanas, en el marco de una sociedad que les bloqueaba espacios de libertad o el acceso a puestos de dirección. Lo mismo en Latinoamérica, las sociedades se hicieron más opresivas. Pero mientras que en los países del centro capitalista esto era motivado por un vigoroso desarrollo capitalista que comprimía la libertad individual, de allí la importancia de la alienación, en países periféricos como el nuestro el problema residía en su deficitario desarrollo. En este sentido, la Universidad se vislumbró como una palanca desde donde impulsar el cambio social.

Sin embargo, el mismo proceso de desarrollo modernizador implicó la aparición de un sujeto contestatario que iría aumentando su inconformismo con el orden social, cuestionando que ese rumbo no hacía más que entronizar el capitalismo dependiente. El autoritarismo creciente de los regímenes políticos fue en el terreno político una respuesta general a la virulenta protesta popular y, al mismo tiempo, una respuesta específica al desafío estudiantil. El "problema de la subversión" comenzó a aflorar desde los tempranos sesenta, posándose las miradas sobre las aulas universitarias.

En este marco, los "azos" argentinos de fines de los años sesenta y comienzos de los setenta constituyeron una respuesta popular a una dictadura que se había cerrado en su proyecto de modernización por vía autoritaria. En nuestro país se produjeron grandes movimientos de alumnos que se volcaron a las calles. Córdoba, Rosario y Tucumán fueron los símbolos más disruptivos de ese alzamiento estudiantil, aunque en las otras grandes urbes también se registró una vibrante acción universitaria, no siempre acompañada por tal sintonía obrera, como lo atestiguó la UBA. En este trabajo pretendimos inscribirlos en el ciclo latinoamericano, marcando similitudes y diferencias, no sólo para reflexionar en clave trasnacional acerca de estos movimientos, sino también para pensarlos en términos locales que van más allá de las naciones.

Como colofón consideramos necesario subrayar dos grandes cuestiones. En primer lugar, la alianza obrera-estudiantil que se construyó en nuestro país fue mucho más dinámica que las alianzas populares que se hilvanaron en las otras naciones del subcontinente, a excepción de la alianza campesina-estudiantil de la sierra peruana. Muestra de ello lo ofrecen los enfrentamientos callejeros

\footnotetext{
${ }^{79}$ Cf. Bonavena, Pablo, Califa, Juan Sebastián y Millán, Mariano, “¿Ha muerto la Reforma? La acción del movimiento estudiantil porteño durante la larga década de 1966 a 1976", Archivos de historial del movimiento obrero y la izquierda, núm. 12, 2018, pp. 73-95.
} 
que desbarataron a las fuerzas del orden corriente, apoderándose de las ciudades, debiendo la dictadura recurrir a la represión militar en un marco de virtual guerra civil. Por ello, cuando se habla de los "azos" es imposible encasillarlos como acontecimientos exclusivamente estudiantiles. Del mismo modo, aunque pueda atribuírsele mayor capacidad dirigente, tampoco pueden ser planteados como acontecimientos puramente obreros. En la mayoría de los casos, y así sucedió en las grandes ciudades aquí analizadas, desplegaron una alianza popular plural que tuvo en su carácter obrero-estudiantil los máximos emblemas de unidad por abajo, con su consiguiente búsqueda de autonomía política de los de arriba.

Como fruto de lo anterior, la dictadura argentina perdió la iniciativa. Sus propuestas universitarias debieron concentrarse en sofocar el incendio que su impericia había colaborado en propagar. Mientras en Brasil, Uruguay, México y Perú se consolidaron los regímenes que enfrentaron los estudiantes, en Argentina hubo un período intermedio, que hizo pensar en la prolongación del ciclo movilizador en los primeros años '70 y que se tornó peligrosamente ilusorio frente al terrorismo de Estado desde 1974. La derrota y la victoria, como es sabido, son siempre conceptos relativos y evanescentes, pudiendo el vencido ser poco tiempo después el vencedor y viceversa. Así le ocurrió a la dictadura con los estudiantes opositores, y así le sucedería a los primeros en breve con una nueva versión de esta. La historia sigue escribiéndose. 